\title{
Microwave Preparation of
}

\section{$\mathrm{SiO}_{2}-\mathrm{B}_{2} \mathrm{O}_{3}-\mathrm{Na}_{2} \mathrm{O}-\mathrm{K}_{2} \mathrm{O}-\mathrm{CaO}-\mathrm{Fe}_{2} \mathrm{O}_{3}-\mathrm{TiO}_{2}$ Glass System}

\author{
Ashis Kumar Mandal ${ }^{1 *}$, Prasanta Kumar Sinha ${ }^{1}$, Santanu Sen ${ }^{1}$, Sitendu Mondal ${ }^{1}$, Chandan Guha ${ }^{2}$ and Ranjan Sen ${ }^{1}$ \\ 1. CSIR-Central Glass and Ceramic Research Institute, Kolkata 700032, India \\ 2. Department of Chemical Engineering, Jadavpur Unirversity, Kolkata 700032, India
}

Received: January 21, 2014 / Accepted: February 17, 2014 / Published: April 25, 2014.

\begin{abstract}
This study reports preparation of glass composition (54.50 wt.\%) $\mathrm{SiO}_{2}$, (10.80 wt.\%) $\mathrm{B}_{2} \mathrm{O}_{3}$, (14.20 wt.\%) $\mathrm{Na}_{2} \mathrm{O}$, (1.20 wt.\%) $\mathrm{K}_{2} \mathrm{O}$, (6.00 wt.\%) $\mathrm{CaO}$, (4.00 wt.\%) $\mathrm{Fe}_{2} \mathrm{O}_{3}$ and (9.30 wt.\%) $\mathrm{TiO}_{2}$ by melt quenching method using direct microwave heating and conventional resistive heating. Study of dielectric loss factor of the glass as function of temperature illustrated increasing loss factor above $370{ }^{\circ} \mathrm{C}, 550{ }^{\circ} \mathrm{C}, 650{ }^{\circ} \mathrm{C}$ and $900{ }^{\circ} \mathrm{C}$, indicating enhanced microwave absorption by the glass at above these temperatures. Chemical analysis results of both the glasses depicted more volatilization loss of volatile ingredients in conventional heating. The study of chemical durability was performed from leachate analysis describing less leaching of $\mathrm{Na}_{2} \mathrm{O}, \mathrm{K}_{2} \mathrm{O}$ and other constituents from glass melted in microwave furnace. Glass transition temperatures $\left(T_{g}\right)$ were found to be $576.3{ }^{\circ} \mathrm{C}$ and $569.5{ }^{\circ} \mathrm{C}$ for glass melted in conventional and microwave heating route, respectively. Laboratory experiment of glass melting utilizing microwave energy as an alternate heating source demonstrated $70 \%-75 \%$ electrical power saving.
\end{abstract}

Key words: Microwave heating, energy efficient glass melting, dielectric constant, loss factor, chemical durability.

\section{Introduction}

Microwave heating has find its application in material processing mainly because of rapid volumetric heating, flexibility in furnace operation (i.e., switching off at maximum temperature) and comfortable working environment owing to only sample heating keeping the cavity cold, substantial reduction in energy consumption, improved mechanical properties and many others $[1,2]$. The difficulty of glass melting using microwave energy is mainly due to low dielectric loss factor of major raw material at room temperature making the material as microwave transparent material. However, the loss factor of glass increases with temperature enabling microwave coupling with materials above "critical temperature" and thereby generating heat within it [3].

\footnotetext{
*Corresponding author: Ashis Kumar Mandal, B.E (Chemical), research fields: microwave melting of glass, glass-ceramic and glass melting process. E-mail: ashis@cgcri.res.in.
}

Hence, glass batches are heated conventionally above $\sim 500{ }^{\circ} \mathrm{C}$ before direct microwave heating for melting [4]. Feasibility study of glass melting by microwave heating has been reported in different glass systems such as, niobium phosphate [5], alumino-phosphate [6], molybdo-phosphate and tungsto-phosphate [7], iron phosphate [8] and inorganic glasses [9] etc.. However, most of researches were carried out in kitchen microwave oven in which proper control of process parameter could not be done.

Present study reports preparation of glass composition (54.47 wt.\%) $\mathrm{SiO}_{2}$, (10.81 wt.\%) $\mathrm{B}_{2} \mathrm{O}_{3}$, (14.16 wt.\%) $\mathrm{Na}_{2} \mathrm{O}$, (1.19 wt.\%) $\mathrm{K}_{2} \mathrm{O}$, (6.02 wt.\%) $\mathrm{CaO}$, (4.05 wt.\%) $\mathrm{Fe}_{2} \mathrm{O}_{3}$ and (9.30 wt.\%) $\mathrm{TiO}_{2}$ using microwave heating. Some of the physical and optical properties were measured and compared with the glass melted from identical batch in resistive heating. The study of power consumption in microwave heating and in conventional resistive heating were presented and discussed. 


\section{Experiments}

\subsection{Conventional Melting of Glass}

The glass was prepared using high purity raw materials like quartz, $\mathrm{H}_{3} \mathrm{BO}_{3}, \mathrm{Na}_{2} \mathrm{CO}_{3}, \mathrm{~K}_{2} \mathrm{CO}_{3}, \mathrm{CaCO}_{3}$, $\mathrm{Fe}_{2} \mathrm{O}_{3}$ and $\mathrm{TiO}_{2}$. Properly mixed raw materials for $60 \mathrm{~g}$ glass was uniaxially pressed to form pellet in a hydraulically operated pellet press and the pellet was placed in a $50 \mathrm{~mL}$ alumina crucible which was subjected to heating in electrical resistive furnace (raising hearth furnace from Bysakh \& Co., India; heating zone: $230 \mathrm{~m} \times 230 \mathrm{~m} \times 300 \mathrm{~m}$ ). B-type thermocouple was fixed with the furnace to monitor the temperature. Power consumption, temperature and time were recorded to generate T-t-P (temperature-time-power) profile in resistive heating. Melting was carried out at $1,300{ }^{\circ} \mathrm{C}$ for $2 \mathrm{~h}$ with a heat up rate $4{ }^{\circ} \mathrm{C} / \mathrm{min}$ and manual stirring was adopted twice with $30 \mathrm{~min}$ interval using silica rod to yield homogeneous glass prior to pouring into a preheated steel mold. The hot glass block was annealed in a muffle furnace at $560{ }^{\circ} \mathrm{C}$, below glass transition temperatures $T_{g}$, for $2 \mathrm{~h}$ followed by controlled cooling to room temperature. The annealed glass was termed as SBNRH (glass prepared in resistive heating).

\subsection{Microwave Melting of Glass}

Identical pellet of glass batch for $60 \mathrm{~g}$ glass was placed inside an alumina crucible insulated by microwave transparent cage insulating box and placed inside a $3 \mathrm{~kW}, 2.45 \mathrm{GHz}$, multimode microwave furnace (from M/S Enerzi Microwave Systems Pvt. Ltd., India, microwave cavity size $367 \mathrm{~mm} \times 349 \mathrm{~mm}$ $\times 386 \mathrm{~mm}$ ). An opening of $20 \mathrm{~mm}$ diameter was made at top cover of insulation box to allow temperature monitoring through a non contact IR (Infrared) pyrometer $\left(260-1,800{ }^{\circ} \mathrm{C}\right)$. The temperature measurement accuracy and repeatability was $\pm 0.3 \%$ of the measured value $+1{ }^{\circ} \mathrm{C}$ with adjustable emissivity $(\varepsilon$ : 0.1-1.0). MW power (Microwave output power) and temperature were recorded by DAQSOFT software in a separate computer. A separate energy meter $(\mathrm{kW}-\mathrm{h}$ meter) was also connected to the input of the electrical circuit to monitor mainly consumption of instant electrical power and total power consumption for overall system including utilities. An integrated closed loop water cooling system was used to cool the microwave cavity, magnetron housing (model: 2M265-M12WJ-Panasonic) and others. The melting of the studied glass was carried out in air atmosphere. Fumes, hot gas generated during melting of batch was exhausted out intermittently by a diaphragm pump. Glass melting was carried out at $1,350{ }^{\circ} \mathrm{C}$ for $1 \mathrm{~h}$. Molten glass was cast into a preheated mold and annealed as explained earlier section. The annealed glass was termed as SBNM (glass melted in microwave furnace).

\subsection{Characterization}

XRD (X-ray diffraction) analysis was performed on 94 X'Pert, PANalytical using Ni-filtered CuKa radiation with wavelength of $1.5406 \AA$ to confirm the sample amorphous characteristic. The scanning was carried out in the range of $10^{\circ}-85^{\circ}$ with a step size of $0.05 \% \mathrm{~min}$.

ICP-AES (inductively coupled plasma atomic emission spectroscopy) (model: Spectro Ciros Vision, Germany) was used for chemical analysis of $\mathrm{Fe}_{2} \mathrm{O}_{3}$, $\mathrm{TiO}_{2}, \mathrm{Na}_{2} \mathrm{O}$ and $\mathrm{K}_{2} \mathrm{O}$; volumetric titrimetry for $\mathrm{SiO}_{2}$ and $\mathrm{B}_{2} \mathrm{O}_{3}$ and complexiometry for $\mathrm{Al}_{2} \mathrm{O}_{3}$ and $\mathrm{CaO}$. Chemical durability was evaluated from leachate analysis by ICP-AES. The bulk glasses were pulverized and sheaved (within mesh No. 40-60). Then, the glasses were washed in acetone and dried at $110{ }^{\circ} \mathrm{C}$ for $2 \mathrm{~h}$. The washed and dried glasses were cooled down inside a desiccator. Each sample of weight $5 \mathrm{~g}$ was taken into a Teflon beaker with $100 \mathrm{~mL}$ deionised water and kept at $90{ }^{\circ} \mathrm{C}$ for 14 days. During the treatment in the above mentioned condition, some of the constituents of the glasses were leached out into the water and these were measured by ICP-AES 
(model: Spectro Ciros Vision, Germany). The relative standard deviation of three successive measurements for all the constituents was in the range from $0.59 \%-0.74 \%$.

Dielectric loss factor and dielectric constant were measured at $2.45 \mathrm{GHz}$ as a function of temperature (up to $1,000{ }^{\circ} \mathrm{C}$ ). A cylindrical cavity, a vector network analyzer, a microwave amplifier, an infrared pyrometer and a computer were employed to carry out the measurement. The cylindrical rod shape sample was placed inside a quartz tube containers and microwave are applied for heating and measuring simultaneously inside a microwave cavity [10]. Typical uncertainty of these measurements is around 2\% in real part and $5 \%$ in imaginary part. For high-temperatures (around $1,000{ }^{\circ} \mathrm{C}$ ), the uncertainty can increase to $10 \%$ because the dimensions of the sample change when the materials are melting. The dimension of the sample is a variable used in the dielectric calculations.

The $T_{g}$ was identified by DSC (differential scanning calorimeter) (NETZSCH STA 449F3) at a heating rate of $10 \mathrm{~K} / \mathrm{min}$ in flowing nitrogen with an accuracy $\pm 1{ }^{\circ} \mathrm{C}$. The refractive indices of glass samples prepared by both methods were measured at five different wavelengths $(473 \mathrm{~nm}, 532 \mathrm{~nm}, 633 \mathrm{~nm}, 1,064 \mathrm{~nm}$ and 1,552 nm) on Prism Coupler (Metricon Model-2010, NJ, USA) fitted with five different lasers as illuminating sources. Three measurements were recorded for each sample and the standard deviation was reported as error of measurement $( \pm 0.0004)$.

FTIR (Fourier transform infrared spectroscopy) measurements of both the glasses were performed on a FTIR spectrophotometer (model: 1615, Perkin Elmer Corporation, USA) with a spectral resolution of $4 \mathrm{~cm}^{-1}$ over a spectral range of $400-2,000 \mathrm{~cm}^{-1}$ to see the structural changes, if any.

Longitudinal velocity $\left(V_{L}\right)$ and shear velocity $\left(V_{T}\right)$ were measured by the ultrasonic pulse-echo method, using Ultrasonic Flaw Detector (model No. EPOCH 1000, Blue Star). An ultrasonic pulse of $20 \mathrm{MHz}$ frequency employed through longitudinal and shear transducers. The Poisson's ratio (v), Young's $(E)$, shear $(G)$ and bulk $(K)$ modulus were calculated applying the measured bulk density $(\rho), V_{L}$, and $V_{T}$ in Eqs. (1)-(4) [11, 12].

$$
\begin{gathered}
v=0.5 \frac{\left(V_{L}^{2}-2 V_{T}^{2}\right)}{\left(V_{L}^{2}-V_{T}^{2}\right)} \\
E=\rho \cdot\left(\frac{3 V_{T}^{2} V_{L}^{2}-4 V_{T}^{4}}{V_{L}^{2}-V_{T}^{2}}\right) \\
G=\rho \cdot V_{T}^{2} \\
K=\frac{\rho}{3} \cdot\left(3 V_{L}^{2}-4 V_{T}^{2}\right)
\end{gathered}
$$

\subsection{T-t-P Profile}

Temperature and variation of MW power with time for melting of $60 \mathrm{~g}$ studied glass using direct microwave heating was presented in Fig. 1. MW power was manually controlled to see the microwave interaction with sample. A rapid temperature increase was observed after $30 \mathrm{~min}$ with slow increase of $\mathrm{MW}$ power at $0.6 \mathrm{~kW}$. A sharp increase of T-t profile at $900{ }^{\circ} \mathrm{C}$ was seen in the Fig. 1, predicting higher dielectric loss factor of the glass above this temperature. Fig. 1 also depicted maximum MW power $\sim 0.60 \mathrm{~kW}$ during the melting till $1,350{ }^{\circ} \mathrm{C}$. However, efficiency of microwave generator was within the range 55\%-65\% of input electrical power. Thus maximum input electrical power would be $\sim 1 \mathrm{~kW}$ during the melting of studied glass in microwave furnace. Fig. 1 further illustrated that total time was within $3 \mathrm{~h}$ during melting including $30 \mathrm{~min}$ initial start up time prior to initiation of heating. Further, operation flexibility in microwave furnace enables easy switch off at high temperature reducing further time and energy.

Temperature and variation of input power with time for the studied glass melted in the resistive heating furnace was displayed in Fig. 2. Heating rate in conventional furnace was restricted to $4{ }^{\circ} \mathrm{C} / \mathrm{min}$ to protect the life of heating element and refractory lining inside the furnace. Soaking time at maximum temperature in conventional melting was almost 


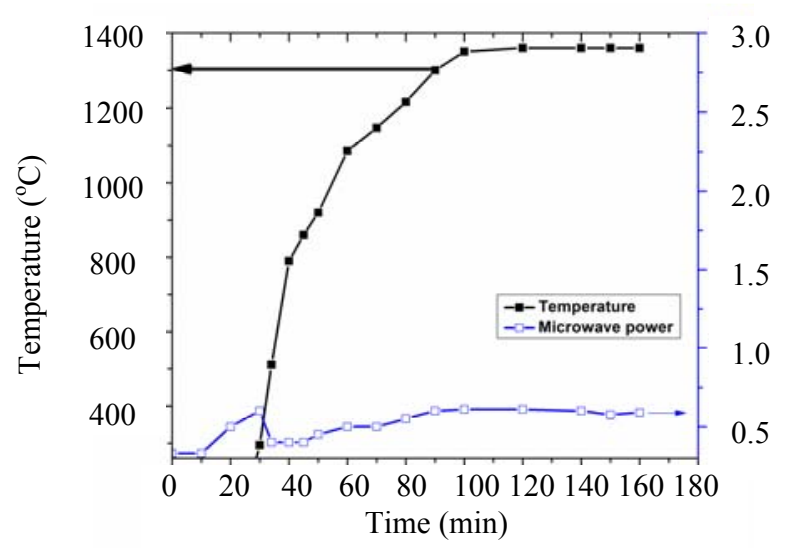

Fig. 1 Temperature and variation of microwave output power with time during microwave melting of glass.

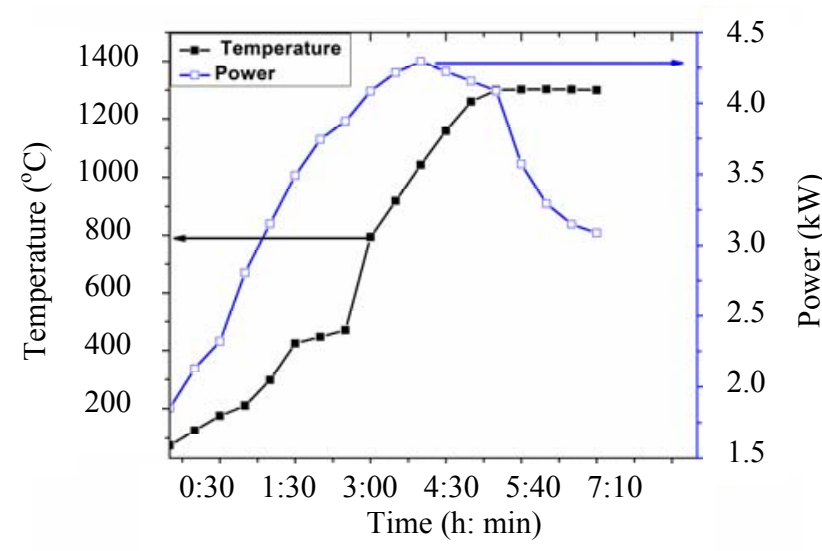

Fig. 2 Temperature and electrical power profile with time for conventional heating in resistance heating furnace.

double the time needed for microwave processing resulting total melting time was around $\sim 7$ h. Fig. 2 also illustrated that maximum instant electrical power in electrical raising hearth furnace was $\sim 4.00 \mathrm{~kW}$ almost four times than that of microwave heating.

A comparison of total power consumption for both the heating method using above furnaces for the equal amount of studied glass was illustrated in Fig. 3. It was clearly seen from the Fig. 4 that the total power consumption was $\sim 26 \mathrm{kWh}$ in the conventional laboratory glass melting process using above raising hearth furnace. Overall melting time was found to be $7 h^{1}$ in conventional glass melting process. In microwave melting, the total power consumption was recorded $6 \mathrm{kWh}$ incorporating additional power load for

${ }^{1}$ Furnace cooling down to room temperature was not considered. utilities, i.e., chilled water system, fume exhaust system. However, total power requirement could be further minimised by changing the design of the microwave furnace using air-cooled magnetron and by placing a small amount of microwave susceptor like $\mathrm{SiC}$ around the crucible, which preheats the raw material before directly absorbing microwave radiation. At higher temperature, microwaves interact with the entire volume of glass at the same rate causing volumetric heating, which further reduces holding time at maximum temperature in glass melting compared to conventional glass melting. Since glass melting is a huge energy consuming process, it would be of great relief if alternate method of producing glass reduces energy requirement substantially. In this context, microwave glass melting could be a potential energy efficient technology saving a significant amount of electrical energy and time, needed for present glass making. Further, microwave melting of glass would eventually contribute to the cleaner environment. However, the difficulty remains in microwave glass melting with proper melting crucible and design of suitable microwave equipment for larger scale glass melting.

\section{Results and Discussion}

\subsection{Microwave Absorption of Material}

Microwave heating is the result of absorption of electromagnetic energy by the material exposed to the microwave field distributed within a reflective cavity. It is based on the power absorbed per unit volume (Eq. (5) $[13,14])$.

$$
P=\sigma\left|E^{2}\right|=2 \pi f \varepsilon_{0} \varepsilon^{\prime}{ }_{r} \tan \delta E^{2} .
$$

where, $E$ is the magnitude of the internal electric field, $\varepsilon_{o}$ is the permittivity of free space, $f$ is the microwave frequency, $\sigma$ is the total effective conductivity, $\varepsilon_{r}^{\prime}$ is the relative dielectric constant, and $\tan \delta$ is the energy loss required to store a given quantity of energy, $\varepsilon_{\text {eff }}^{\prime \prime}$ 


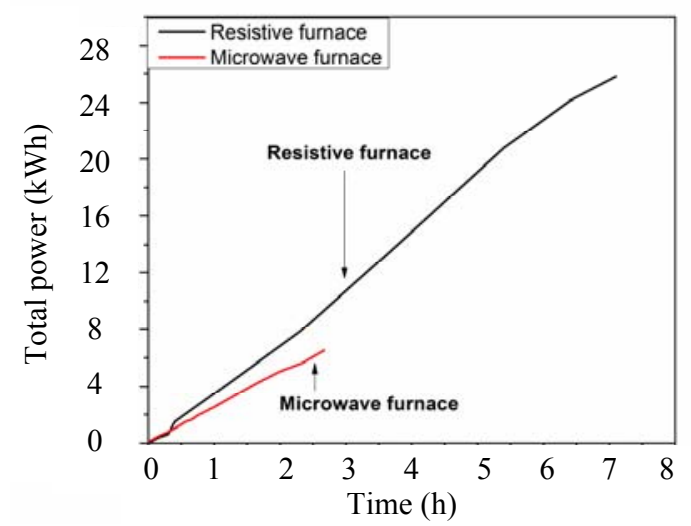

Fig. 3 Total power consumption profile with temperature; for resistance heating and for microwave heating.

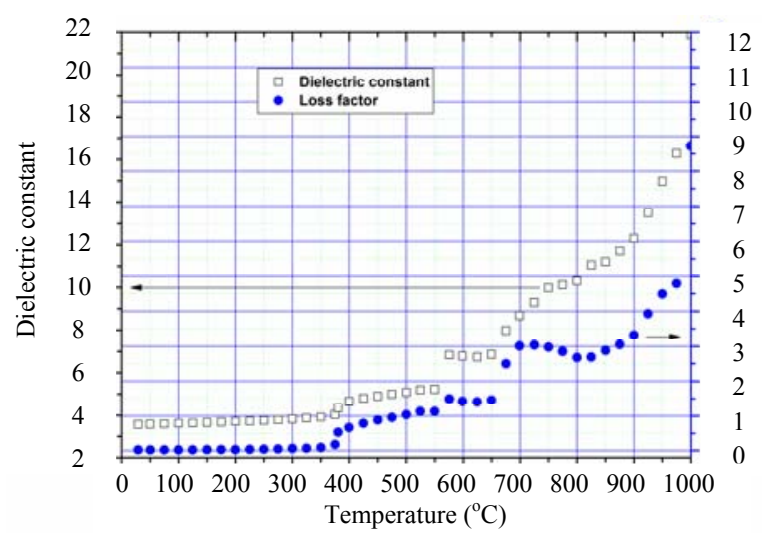

Fig. 4 Dielectric constant and loss factor for the studied glass was measured around $2.45 \mathrm{GHz}$ as a function of temperature up to $1,000{ }^{\circ} \mathrm{C}$.

$\left(=\varepsilon_{r}^{\prime} \cdot \tan \delta\right)$ is the relative effective dielectric loss factor. It is clearly seen from the above Eq. (5) that the dielectric properties $\left(\varepsilon_{o}, \varepsilon_{r}^{\prime}\right.$ and $\left.\tan \delta\right)$ assume a significant role in determining the extent of power absorbed by a material.

Fig. 4 portrayed the dielectric constant and dielectric loss factor as function of temperature (up to $1,000{ }^{\circ} \mathrm{C}$ ) for this glass. Dielectric loss factor, one of the important parameters, indicates the degree of microwave absorption by the material to generate heating within it for a fixed frequency $(2.45 \mathrm{GHz})$ and a given electrical field within the material. The Fig. 4 depicted that loss factor increased at $\sim 370{ }^{\circ} \mathrm{C}, \sim 560{ }^{\circ} \mathrm{C}$, $\sim 650{ }^{\circ} \mathrm{C}$ and $\sim 900^{\circ} \mathrm{C}$ suggesting enhance microwave absorption and heating of glass at these temperatures. Sharp increase of loss factor 0 at around $900{ }^{\circ} \mathrm{C}$ corroborated the rapid heating observed from the T-t profile in microwave heating in Fig. 1. However, microwave interaction with batch material at lower temperature was found different due to the presence of different raw material (i.e., carbonate, $\mathrm{H}_{3} \mathrm{BO}_{3}$ ).

\subsection{Comparison of Properties}

Fig. 5 displayed photograph of $1 \mathrm{~mm}$ thick polished glass $(15 \mathrm{~mm} \times 20 \mathrm{~mm})$ melted in a conventional resistance-heating (SBNRH) and in microwave heating (SBNM). In Fig. 5, improved homogeneity of SBNM was seen, apparently compared to SBNRH. Though the SBNM was prepared without employing any mechanical stirring, improved homogeneity was due to the result of microwave induced "self-stirring" effect [15].

The XRD patterns for the SBNRH and SBNM samples, shown in Fig. 6, depicting identical broad humps confirmed the amorphous nature of the samples. The absence of sharp Bragg peak in the XRD profile of SBNM, similar to that of SBNRH, confirmed no unmelted crystalline phase left within the glass melted using microwave.

Chemical analysis results for SBNM and SBNRH samples were listed in Table $1 . \mathrm{B}_{2} \mathrm{O}_{3}$ and $\mathrm{Na}_{2} \mathrm{O}$ were found less in SBNRH glass illustrating higher evaporation loss of these ingredients in conventional melting. $\mathrm{Al}_{2} \mathrm{O}_{3}$ was found $6.47 \%$ in $\mathrm{SBNRH}$ and $1.56 \%$ in SBNM sample. In conventional heating, heat travels from the heating element to the material by means of

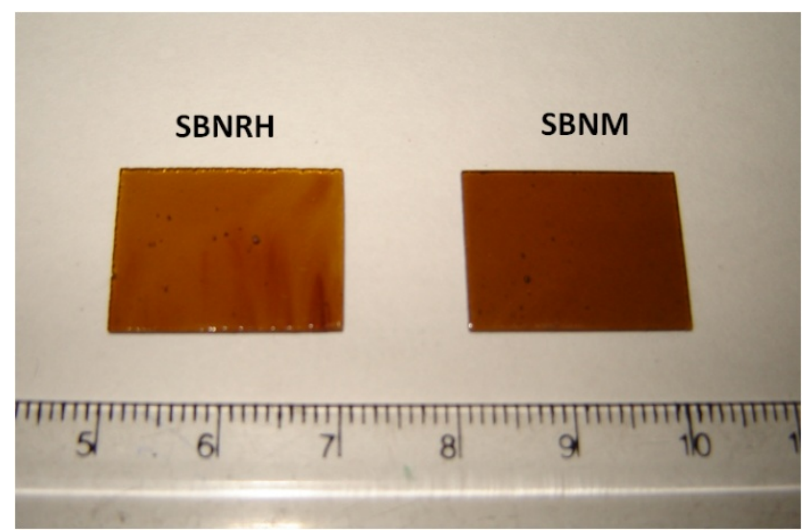

Fig. 5 Photographs of polished SBNRH and SBNM glass samples. 


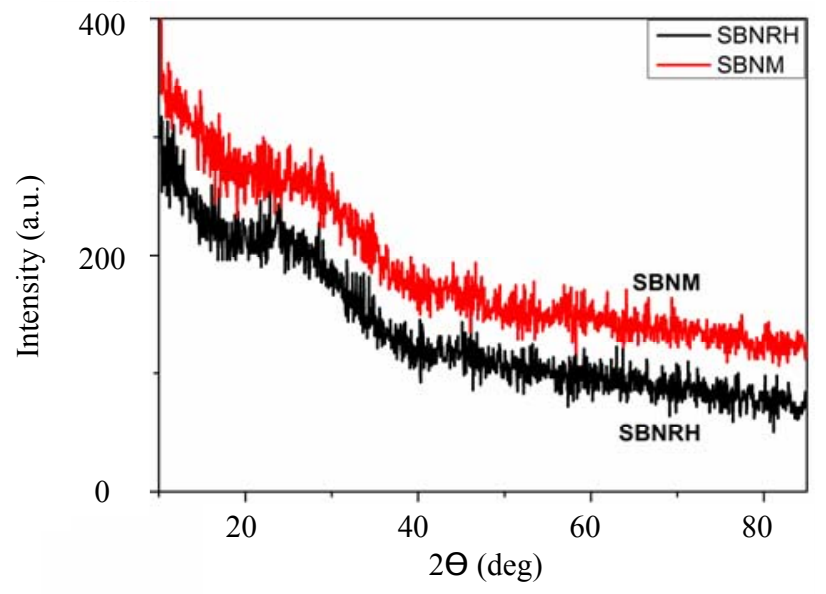

Fig. 6 XRD curves for SBNM and SBNRH samples.

radiation, conduction, convection mechanism and thus temperature of the crucible wall remains higher than the molten glass. This higher wall temperature together with higher melting time contributed higher leaching of $\mathrm{Al}_{2} \mathrm{O}_{3}$ into the molten glass in conventional melting. In microwave heating, heat generates within the material internally resulting in volumetric heating within the glass without heating the alumina crucible owing to its low dielectric loss factor. Due to this rapid internal heating, temperature gradient in microwave heating exists in the reverse direction than that of conventional heating resulting less temperature in crucible wall and in the top surface of molten glass. Thus, less crucible wall temperature along with less melting time favour low contamination of alumina into the glass melt in microwave heating. This reverse temperature gradient also contributes less evaporation of volatile ingredients of glass in microwave heating. However, slightly higher melting temperature is needed in case of microwave melting due to less surface temperature of molten glass.

The chemical durability of both the glasses was evaluated from leachate analysis by Inductively Coupled Plasma-Atomic Emission Spectroscopy. The results, as shown in the Table 2, illustrated higher concentration of $\mathrm{Al}_{2} \mathrm{O}_{3}, \mathrm{CaO}, \mathrm{Fe}_{2} \mathrm{O}_{3}, \mathrm{TiO}_{2}, \mathrm{Na}_{2} \mathrm{O}$ and $\mathrm{K}_{2} \mathrm{O}$, leached out into water from the SBNRH sample signifying higher leaching rate of above constituents from SBNRH sample. This indicated improved chemical durability of glass was prepared in microwave heating. This may be explained that more evaporation of glass former, i.e., $\mathrm{SiO}_{2}$ and $\mathrm{B}_{2} \mathrm{O}_{3}$ the main building block in glass, weaken the glass structure in conventional heating method.

Fig. 7 exemplified DSC thermograph for both the glasses SBNRH and SBNM. $T_{g}$ was identified $569.5{ }^{\circ} \mathrm{C}$ and $576.3{ }^{\circ} \mathrm{C}$ for SBNM and SBNRH samples, respectively. $T_{g}$ value for SBNM was observed less due to difference in the composition of the glasses resulting from low loss of volatile constituents of glass. Higher presence of $\mathrm{Al}_{2} \mathrm{O}_{3}$ in $\mathrm{SBNRH}$ owing to leaching from crucible wall, also contributed the higher $T_{g}$ in SBNRH.

The some of the physical, optical and elastic properties of SBNM and SBNRH were listed in Table 3. Optical properties for SBNRH and SBNM samples were calculated from their measured refractive indices using relevant expressions and were presented in Table 3 .

Fig. 8 portrayed dispersion curves, obtained by fitting the measured refractive indices with the

Table 1 Chemical analysis results for SBNRH and SBNM samples.

\begin{tabular}{lll}
\hline Composition (wt.\%) & SBNRH & SBNM \\
\hline $\mathrm{SiO}_{2}$ & $56.36( \pm 0.08)$ & $58.88( \pm 0.08)$ \\
$\mathrm{B}_{2} \mathrm{O}_{3}$ & $7.92( \pm 0.04)$ & $9.13( \pm 0.04)$ \\
$\mathrm{Na}_{2} \mathrm{O}$ & $10.92( \pm 0.04)$ & $12.02( \pm 0.04)$ \\
$\mathrm{K}_{2} \mathrm{O}$ & $0.68( \pm 0.03)$ & $0.82( \pm 0.03)$ \\
$\mathrm{CaO}$ & $4.82( \pm 0.04)$ & $5.03( \pm 0.04)$ \\
$\mathrm{Fe}_{2} \mathrm{O}_{3}$ & $3.65( \pm 0.03)$ & $3.65( \pm 0.03)$ \\
$\mathrm{TiO}_{2}$ & $8.91( \pm 0.04)$ & $8.57( \pm 0.04)$ \\
$\mathrm{Al}_{2} \mathrm{O}_{3}$ & $6.47( \pm 0.03)$ & $1.56( \pm 0.03)$ \\
\hline
\end{tabular}


Table 2 The concentration (in ppm) of different constituents present in deionised water after 14 days insertion of SBNRH and SBNM glasses at $90^{\circ} \mathrm{C}$.

\begin{tabular}{lllllll}
\hline Leachate from samples & $\mathrm{Al}_{2} \mathrm{O}_{3}$ & $\mathrm{CaO}$ & $\mathrm{Fe}_{2} \mathrm{O}_{3}$ & $\mathrm{TiO}_{2}$ & $\mathrm{Na}_{2} \mathrm{O}$ & $\mathrm{K}_{2} \mathrm{O}$ \\
\hline SBNM & 31 & 19 & 10 & 15 & 131 & 21 \\
SBNRH & 59 & 68 & 21 & 35 & 377 & 74 \\
\hline
\end{tabular}

Table 3 Glass transition temperature, optical properties and elastic properties for SBNRH and SBNM are presented.

\begin{tabular}{lll}
\hline Property & SBNRH & SBNM \\
\hline Measured Refractive index $(n)$ at & & \\
$473 \mathrm{~nm}( \pm 0.0004)$ & 1.5969 & 1.6006 \\
$532 \mathrm{~nm}( \pm 0.0004)$ & 1.5904 & 1.594 \\
$633 \mathrm{~nm}( \pm 0.0004)$ & 1.5827 & 1.586 \\
$1,064 \mathrm{~nm}( \pm 0.0004)$ & 1.5691 & 1.573 \\
$1,552 \mathrm{~nm}( \pm 0.0004)$ & 1.5624 & 1.5656 \\
\hline Estimated Refractive indices at & & \\
$n_{d-587.6}( \pm 0.0005)$ & 1.5860 & 1.5895 \\
$n_{F-486.1}( \pm 0.0005)$ & 1.5953 & 1.5988 \\
$n_{C-656.3}( \pm 0.0005)$ & 1.5814 & 1.5848 \\
$\mathrm{n}_{\mathrm{d}-1}$ & 0.586 & 0.59 \\
Mean dispersion $\left(n_{F}-n_{C}\right)$ & 0.014 & 0.014 \\
Abbe No. & 42.16 & 42.10 \\
Reflection loss $(\%)$ & 5.17 & 5.13 \\
\hline Elastic properties & & \\
Longitudinal velocity $(\mathrm{m} / \mathrm{s})$ & 5,776 & 5,813 \\
Shear velocity $(\mathrm{m} / \mathrm{s})$ & 3,448 & 3,505 \\
Young's modulus $(E, \mathrm{GPa})$ & 78.90 & 80.20 \\
The Poisson's ratio $(v)$ & 0.219 & 0.235 \\
Shear modulus $(G, \mathrm{GPa})$ & 90.07 & 93.76 \\
Bulk modulus $(K, \mathrm{GPa})$ & 46.90 & 50.46 \\
Glass transition temperature, $T_{g}\left( \pm 1{ }^{\circ} \mathrm{C}\right)$ & 576.3 & 569.5 \\
\hline
\end{tabular}

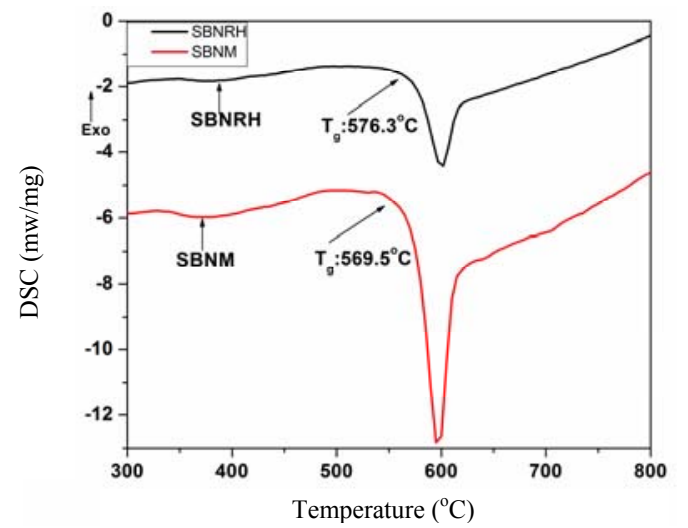

Fig. 7 DSC thermographs for SBNRH and SBNM sample.

Cauchy Eq. (6). The refractive indices at standard wavelengths $n_{d}$ (at $587.6 \mathrm{~nm}$ ), $n_{F}$ (at $486.1 \mathrm{~nm}$ ) and $n_{C}$ (at $656.3 \mathrm{~nm}$ ) were estimated from the curve.

$$
n(\lambda)=A+\frac{B}{\lambda^{2}}+\frac{C}{\lambda^{2}}+\cdots
$$

where, $n$ is refractive index at wavelength $\lambda$. The Abbe number $V$ of a material is defined as Eq. (7):

$$
V=\frac{\left(n_{d}-1\right)}{\left(n_{F}-n_{c}\right)}
$$

where, $n_{d}, n_{F}$ and $n_{C}$ are the refractive indices of the samples at the wavelengths $587.6 \mathrm{~nm}, 486.1 \mathrm{~nm}$ and $656.3 \mathrm{~nm}$, respectively. Abbe number was calculated and found very similar for both SBNRH and SBNM as 42.16 and 42.10 , respectively. Mean diffraction and reflection loss for SBNRH and SBNM samples were also found similar.

Elastic properties like $v$, Young's (E)-shear (G)-bulk (K) modulus were calculated and listed in Table 3. The identical or slightly higher value of these properties in the microwave prepared glass confirmed 


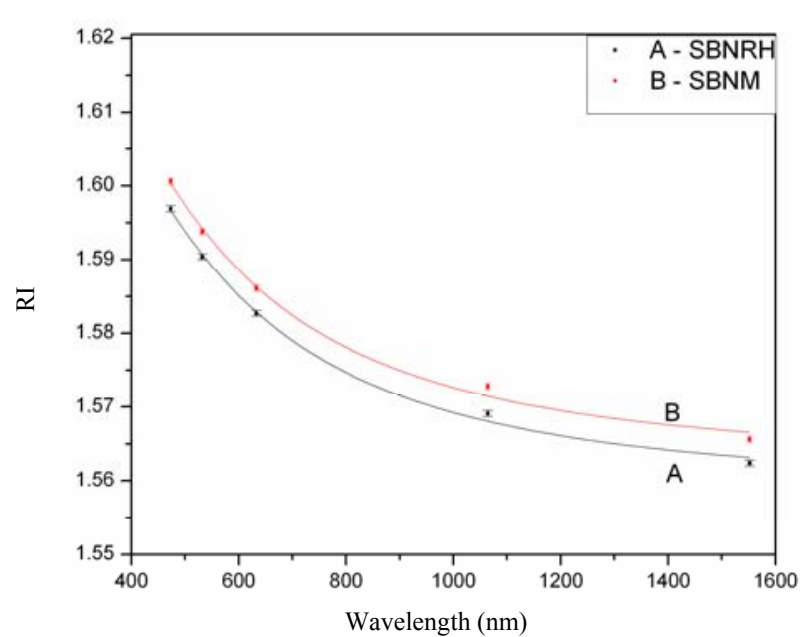

Fig. 8 RI vs. wavelength fitted by Cauchy curve fitting equation.

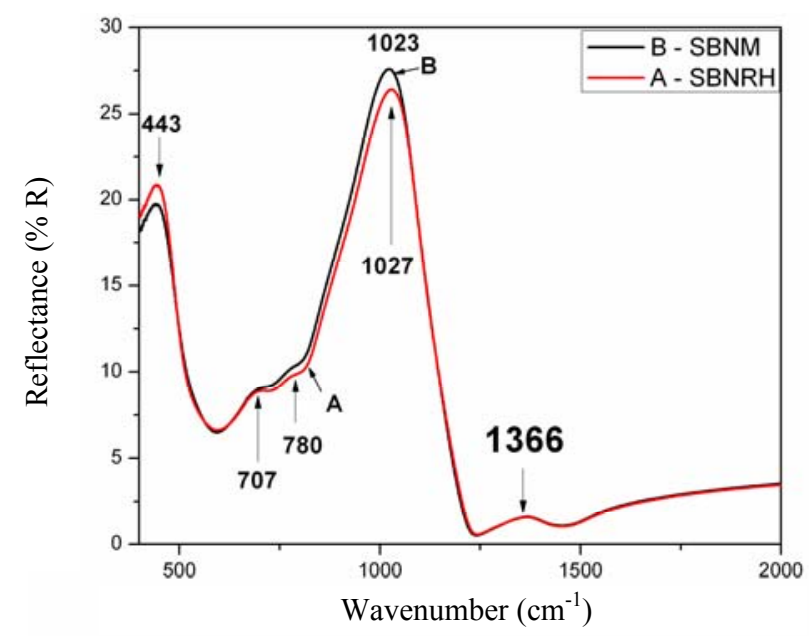

Fig. 9 FTIR reflectance spectra of studied samples in the wave number range $400-2,000 \mathrm{~cm}^{-1}$.

that similar glass or slightly improved property of glass could be prepared in microwave heating.

The FTIR reflectance spectra of samples SBNRH and SBNM were presented in Fig. 9. Both the spectra of these glasses consisted of similar broad and sharp bands in different regions $\left(400-2,000 \mathrm{~cm}^{-1}\right)$ confirming identical structure. FTIR spectra for both glasses showed the presence of silicate peak centered at $1,022 \mathrm{~cm}^{-1}$ and Si-O-Si bend at around $443 \mathrm{~cm}^{-1}$ [16] The bands at around $1,020 \mathrm{~cm}^{-1}$ peak were attributed to a stretching vibration of B-O-Si linkage [17]. The peak $\sim 700 \mathrm{~cm}^{-1}$ was due to the bending of B-O-B linkages in the borate glassy network [18]. The boroxol ring appeared at $780 \mathrm{~cm}^{-1}$ [19]. The band around $1,360 \mathrm{~cm}^{-1}$ was assigned to B-O stretching vibration of trigonal $\left[\mathrm{BO}_{3}\right]$ unites $[20,21]$.

\section{Conclusions}

A glass containing $\mathrm{SiO}_{2}-\mathrm{B}_{2} \mathrm{O}_{3}-\mathrm{Na}_{2} \mathrm{O}-\mathrm{K}_{2} \mathrm{O}-\mathrm{CaO}-$ $\mathrm{Fe}_{2} \mathrm{O}_{3}-\mathrm{TiO}_{2}$ was successfully melted using direct microwave heating. Dielectric constant and loss factor as function temperature depicted increase of these properties at $370{ }^{\circ} \mathrm{C}, 550{ }^{\circ} \mathrm{C}, 650{ }^{\circ} \mathrm{C}$ and $900{ }^{\circ} \mathrm{C}$, indicating enhanced microwave absorption with this glass composition above these temperatures. Similar glass was also prepared from identical batch in conventional resistive heating. Physical properties and structure of both the glasses were found similar. Glass melted in microwave heating was found closer chemical composition as prescribed in batch, improved chemical durability and lower glass transition temperature. Substantial less consumption of energy and shorter processing time was demonstrated in laboratory scale glass melting in microwave furnace. Thus, microwave processing of glass could be a potential method for reduction of energy consumption and time.

\section{Acknowledgements}

This work was funded by SupraInstitutional Network Project ESC0202 (GLASSFIB) of Council of Scientific and Industrial Research, India. Authors are thankful to the Director, CSIR-CGCRI for his kind support and encouragement to pursue this work. Authors also like to thank Mr. A. R. Molla, Dr. K. Biswas, Dr. K. Annapurna for their help in characterization of glass samples. Authors sincerely acknowledge the contribution of staff in GSTS, CSIR-CGCRI for their help as when required. Authors are thankful to Prof. J. M. Catala Civera for measurement of dielectric properties.

\section{References}

[1] Sutton, W. H. Microwave Processing of Ceramic 
Materials. Cer. Bull. 1987, 68, 376-386.

[2] Thostenson, E. T.; Chou, T. W. Microwave Processing: Fundamentals and Applications. Composites: Part A 1999, 30, 1055-1071.

[3] Siligardi, C. D.; Arrigo, M. C.; Leonelli, C.; Pellacani, G. C.; Cross, T. E. Bulk Crystallization of Glasses Belonging to the Calcia-Zirconia-Silica System by Microwave Energy. J. Am. Ceram. Soc. 2000, 83, 1001-1003.

[4] Knox, M. P.; Copley, G. J. Use of Microwave Radiation for the Processing of Glass. Glass Technol. 1997, 38, 91-96.

[5] Ghussn, L.; Martinelli, J. L. A Novel Method to Produce Niobium Phosphate Glasses by Microwave Heating. $J$ Mater Sci. 2004, 39, 1371-1376.

[6] Mandal, A. K.; Biswas, K.; Annapurna, K.; Guha, C.; Sen, R. Preparation of Alumino-Phosphate Glass by Microwave Radiation. J. Mater. Res. 2013, 28(14), 1955-1961.

[7] Chenu, S.; Rocherullè, J.; Lebullenger, R.; Merdrignac, O.; Chevire, F.; Tessier, F.; et al. Synthesis and Characterization of Tin Containing Molybdophosphate and Tungstophosphate Glasses. J. Non-Cryst. Solids 2010, 356, 87-92.

[8] Almeida, F. J. M.; Martinelli, J. R.; Partiti, C. S. M. Characterization of Iron Phosphate Glasses Prepared by Microwave Heating. J. Non-Cryst. Solids 2007, 353, 4783-4791.

[9] Vaidhyanathan, B.; Ganguli, M.; Rao, K. J. A Nobel Method of Preparation of Inorganic Glasses by Microwave Irradiation. J. Solid State Chem. 1994, 113, 448-450.

[10] Peñaranda-Foix, F. L.; Janezic, M. D.; Civera, J. M. C.; Canós, A. J. Full-Wave Analysis of Dielectric-Loaded Cylindrical Waveguides and Cavities Using a New Four-Port Ring Network. IEEE T Microw. Theory 2012, 60, 2730-2740.

[11] Varshneya, A. Fundamentals of Inorganic Glasses;
Academic Press: New York, 1994.

[12] Afifi, H.; Marzouk, S. Ultrasonic Velocity and Elastic Moduli of Heavy Metal Tellurite Glasses. Mater. Chem. Phys. 2003, 80, 517-523.

[13] Clark, D. E.; Folz, D. C.; West, J. K. Processing Materials with Microwave Energy. Mat. Sci. Eng. A-Struct. 2000, 287, 153-158.

[14] Rao, K. J.; Vaidhyanathan, B.; Ganguli, M.; Ramakrishnan, R. K. Synthesis of Inorganic Solids Using Microwaves. Chem. Mater. 1999, 11, 882-895.

[15] Mandal, A. K.; Agrawal, D.; Sen, R. Preparation of Homogeneous Barium Borosilicate Glass Using Microwave Energy. J. Non-Cryst. Solids 2013, 371, 41-46.

[16] Abiraman, S.; Varma, H. K.; Kumari, T. V.; Umashankar, P. R.; John, A. Preliminary in vitro and in vivo Characterizations of a Sol-Gel Derived Bioactive Glass-Ceramic System. Bull. Mater. Sci. 2002, 25, 419-429.

[17] Tenny, A. S.; Wong, J. Vibrational Spectra of Vapor-Deposited Binary Borosilicate Glasses. J. Chem. Phys. 1972, 56, 5516-5523.

[18] Dwoeidari, H.; Abou, Z.; Damraway, E. I. Effect of Gamma Radiation and Thermal Treatment on Some Physical Properties of $\mathrm{ZnO}-\mathrm{PbO}-\mathrm{B}_{2} \mathrm{O}_{3}$ Glasses. J. Phys. D: Appl. Phys. 1991, 24, 2222-2228.

[19] Silim, H. A. Structure and Properties of BaO- $\mathrm{B}_{2} \mathrm{O}_{3}-\mathrm{Al}_{2} \mathrm{O}_{3}-\mathrm{NaCl}$ Glass System Egypt. J. Sol. 2003, 26, 15-24.

[20] Nolan, M.; Perova, T. S.; Moore, R. A.; Beitia, C. E.; McGilp, J. F.; Gamble, H. S. Spectroscopic Investigations of Borosilicate Glass and Its Application as a Dopant Source for Shallow Junctions. J. Electro Chem. Soc. 2000, 147, 3100-3105.

[21] Lal, R.; Sharma, N. D.; Chandra, K. Mössbauer and Infrared Studies of Some Glasses and Glass-Ceramics from the $\mathrm{MnO}_{(40-\mathrm{X}) \mathrm{Y}} \mathrm{Fe}_{2} \mathrm{O}_{3.10} \mathrm{Al}_{2} \mathrm{O}_{3.50} \mathrm{~B}_{2} \mathrm{O}_{3}$ System. Indian J. Pure Appl. Phys. 2004, 42, 498-505. 